\title{
REVIEW
}

\section{Research on Internet Public Opinion and Social Governance in the Big Data Era}

\section{Shengliang $\mathrm{Wu}^{*}$}

Sias University, Xinzheng, Henan, 451150, China

\begin{tabular}{ll}
\hline ARTICLE INFO & ABSTRACT \\
\cline { 2 - 2 } $\begin{array}{l}\text { Article history } \\
\text { Received: } 9 \text { August } 2019\end{array}$ & $\begin{array}{l}\text { In the development of modern society, the Internet public opinion pres- } \\
\text { ents the characteristics of cross-platform, multi-node, complex, etc. There } \\
\text { are quite a few types of online public opinion with short duration, and the } \\
\text { Revised: } 25 \text { August } 2019 \\
\text { content has certain conflicts. The network opinion has greatly changed in } \\
\text { Accepted: } 10 \text { October } 2019\end{array}$ \\
$\begin{array}{l}\text { the development of society, but there are still many pressures of public } \\
\text { opinion. The paper studies the Internet public opinion and social gover- } \\
\text { nance in the big data era, and hopes to realize the scientificity of social } \\
\text { governance. }\end{array}$
\end{tabular}

Keywords:

Big data era

Internet public opinion

Social governance

\section{Introduction}

$\mathrm{I}$ $\mathrm{n}$ the rapid development of social economy, Internet technology has been widely used in various fields, and the masses can express their own public interest needs on the Internet, which makes the public opinion in the social media platform gather, collide and erupt. In the Internet era, WeChat is a representative of social media platform. The functions of official account, group chat, friend circle, etc. play a crucial role in the process of generating Internet public opinion, and Weibo is important in the spread of emergencies ${ }^{[1]}$. Therefore, in the environment of big data, the social media platform has generated Internet public opinion, and government departments should strengthen social governance.

\section{Overview of Internet Public Opinion and Network Social Governance}

Internet public opinion refers to social conditions and public opinions in the social network platform, which mainly involves two aspects, namely: Firstly, using the Internet to publish and disseminate news events and hotspot information; Secondly, the viewpoints, attitudes and opinions expressed by the masses. At this stage, the Internet and social network have been widely used in the development of society, and the dissemination speed of news information has been greatly improved. However, many emerging online media are featured with low requirements, large user base, large amount of information, real-time, etc. Everyone can produce and spread news ${ }^{[2]}$. Network social factors mainly include network information, network be-

*Corresponding Author:

Shengliang $\mathrm{Wu}$,

Correspondence address: Sias University, No. 168 East Renmin Road, Xinzheng, Henan, 451150, China;

E-mail:wsl431@163.com. 
havior and social relations, and other information. Moreover, Internet public opinion reflects the viewpoints and contradictions in the network society. In the big data era, China has formed a large and complex network society, which involves quite a lot contents, such as information dissemination, social interaction, economic and social development, social management and so on. Internet public opinion governance refers to monitoring and managing social opinion information in network communication, while network social governance refers to adjusting network information, network behavior governance, social relations, etc., and fully exerting the role of network information dissemination platform. ${ }^{[1]}$

\section{The Characteristics and Value of Big Data}

\subsection{The Characteristics of Big Data}

At present, there is no clear definition of big data in the academic world. A large number of people think that the characteristics of big data are mainly reflected in the following aspects: Firstly, needing a lot of data; secondly, utilizing data sources stored in the related structures; thirdly, updating and analyzing the data in time. In the development of modern society, the total amount of data refers to an exponential increase trend. The integration of many unstructured data makes the data complex, which greatly improves the speed of data generation, analysis and processing.

\subsection{The Value of Big Data}

The value of big data is mainly to effectively filter and abstract related data, and use visual technology to present these data. The amount of data is relatively large, which lowers the value and density of big data, but big data has a strong value-added effect ${ }^{[3]}$. Big data analysis, involving many fields, can predict and analyze according to data trends and patterns. Therefore, big data analysis not only stays on the surface, but also needs to analyze various data in depth and fully exploit the potential value of the data.

\section{The Characteristics of Internet Public Opinion in the Big Data Era}

\subsection{Diversification of Internet Public Opinion}

Traditional Internet public opinion mainly refers to public affairs and public issues, while public issues refer to social problems corresponding to individual problems, which greatly affect the daily life of the masses and the development of social economy. In the development of the Internet era, Internet public opinion includes not only social problems related to the common interests of the masses, but also problems in the field of consciousness such as social thoughts and moral ideas. Through relevant research, it is found that the types of Internet public opinion hotspots mainly include social contradictions, public management, public security and anti-corruption, as well as sports and entertainment, public figures and military diplomacy. In addition, Internet public opinion involves social ethics, labor disputes, ideological disputes and other social contradictions, and all sectors of society should pay attention to the social impact of public opinion. ${ }^{[2]}$

\subsection{Internet Public Opinion with Short Duration}

In the development of social economy, Internet technology has been widely used in the masses' daily life. It is real-time and interactive, providing the masses with diverse information so that everyone can make reasonable choices and discuss issues according to the actual situation. However, in the context of the increasing hot public opinion events in social public affairs, the duration of individual hot issue has become shorter and shorter, and there is less than a week from outbreak to fade of the public opinion. The masses have a relatively low degree of concentration on the subjects of little change, but mixed with new topics and elements, the subjects will be able to inspire everyone's interest. Under the background of the increasing network hotspots, the people concentrate on the new hot events, but no longer pay attention to the continuity of a single event. Internet public opinion reflects the emotions of the masses, but it is characterized by instability. The opinions of the masses will continue to change during the development of the incident. Many public issues cannot fully reflect Internet public opinion, and the people can express their opinions and attitudes toward public issues, but their demands are greatly different, which leads to a certain conflict in the public opinion collected in the network.

\subsection{Online Opinion Leaders Continue to Change}

In the rapid development of social media, the influence of opinion leaders in social media is getting stronger and stronger. The information and comments published by online opinion leaders have been widely concerned by netizens, which has led to the exponent spread of social networks and developed into the masses' common concerns, further developing the events and topics into public issues ${ }^{[4]}$. At the same time, opinion leaders in social media platforms play the role of information transmitters and gatekeepers. In the process of second information dissemination, opinion leaders often add their own opinions 
to discuss social issues in social media platforms, attracting more people to be concerned about social events. In addition, in the rapid development of the social economy, the Internet has been effectively applied in various fields of society, and network opinion leaders are changing day by day, but the influence of online opinion leaders on the setting of public issues still exists. Under the background of the increasing popularity of WeChat social media platform, government departments are paying more and more attention to online rumor governance, which makes "influencer" of Weibo replaced by private, civilian and automated dissemination of We-Media official accounts of WeChat. We Media has been given a new voice of the public opinion field. ${ }^{[3]}$

\subsection{Traditional Media Lay Out and New Media Platform Promotes Internet Public Opinion}

In the big data era, the ability of traditional media to set agendas in the social media era is steadily weakening, and public events in social media platforms have received widespread attention from all sectors of society, which still rely on traditional media reporting and promoting public events, and erupting in social media platforms. The social media platforms are generally used by traditional media to spread information such as facts, opinions and positions through Weibo account and WeChat official account. In the development of the new era, many traditional media in China have actively deployed new media content platforms such as WeChat and client, using the carriers of text, pictures, sound and video to implement the spread form of "mobilization", "fragmentation" and "matrix", which is conducive to ease public opinion. ${ }^{[4,5]}$

\section{New Challenges Faced by Internet Public Opinion and Network Social Governance in the Big Data Era}

\subsection{The Government Uses the Network Platform to Become the Leader of Information Release}

In the big data era, the development of social network media platforms is very rapid. The government has changed the identity of the only publisher of information and data. The business sector, social platforms and the masses upload large amounts of data, and relevant fields collect and mine large amounts of data and analyze them, publish platforms and provide consulting services. The conclusions have similar characteristics in this process, but there are certain differences in the data collection channels, making the statistical data methods different. And the data conclusions and government statistics will be different, which, to a large extent, threatens the authority of the government ${ }^{[5]}$. In addition, big data is characterized by noise and low density. In order to better protect the necessary confidentiality and enable the masses to have the right to know about data resources, government departments need to resolve the problems that there is limited authority of information resources and that the people are curious, which has gradually developed into a problem of strengthening Internet public opinion management in the process of social governance.

\subsection{Internet Public Opinion Monitoring is Diffi- cult}

In the development of modern society, online news has gradually become an important channel for news dissemination, and has presented many new features, which has brought difficulties to Internet public opinion monitoring. Firstly, there are many online news dissemination platforms and the main body of dissemination is popular. Communication tools such as BBS, QQ, Weibo and WeChat have become important tools for the masses to acquire and disseminate information. The people can forward, load and comment on news with only a few keystrokes, which has greatly expanded the spread range of news and increased the speed of news dissemination; secondly, under the background of rapid improvement of imaging technology level, the communication content presents diverse characteristics. At this stage, the functions of video equipment and mobile phones are getting stronger and stronger, and the masses can get the latest news pictures and images conveniently. The form of online news dissemination is also increasing, including not only text and illustrations, but also high-definition videos and pictures, which has left a deeper impression on the masses and made the news more convincing; finally, with the rapid development of search engines, information acquisition is more convenient and presents the characteristic of initiative. Search engines integrate with language recognition and artificial intelligence technology by using big data, cloud computing, etc., and quickly search for more information using language and pictures, enabling the masses to actively accept information and search and comment on relevant information accurately and quickly.

\subsection{Internet Public Opinion Analysis and Re- sponse are Increasingly Difficult}

In the development of the new era, the government departments face great challenges. They need to grasp the dynamics of Internet public opinion in an accurate, comprehensive and timely manner, improve the ability 
of public opinion information monitoring and analysis, and provide support for public opinion. In addition, the response method of network public opinion can't meet the relevant requirements. In the traditional Internet public opinion response process, many government departments block information by deleting and forbidding posts. In the big data era, information is not transmitted to various websites and passively waits for browsing, but is spread rapidly to many network platforms in people's phones, making it easier to delete websites and information. In addition, the spread of online news is relatively wide and the speed is very fast, which brings difficulties to information blocking, making the government departments face great challenges in response speed and way. ${ }^{[6]}$

\section{Optimization Measures of Internet Public Opinion and Social Governance in the Big Data Era}

\subsection{Correctly Understanding the Negative Effects of Internet Public Opinion}

In the big data era, social media has developed very rapidly, providing an open and equal environment for the masses to express their social and political attitudes, but it has gradually developed into a way to create rumors. In the context of social media, the problem of group polarization is becoming more and more serious. For example, a lot of information cannot enter the closed social environment such as WeChat friend circle and WeChat group chat. Radical and conservative attitudes will affect the group's tendency, which seriously inhibits public opinion and has an impact on the social governance of government departments ${ }^{[6]}$. Therefore, social media has broadened the sources and ways of public opinion to a certain extent, but relevant personnel need to recognize the negative effects of Internet public opinion in the social media environment, and implement collection methods such as Internet public opinion collection, citizen surveys, and hearings to provide everyone with more opportunities for expression of needs and interests.

\subsection{Improving the Credibility of Government In- formation Dissemination}

In the process of governing the Internet public opinion, in the context of the close attention of the masses, influenced by the Internet communication, there have been many rumors that seriously affect the development of the country and society. Therefore, in order to correctly guide Internet public opinion, relevant departments need to establish transparent channels for information disclosure, timely re- lease comprehensive, accurate and effective information, and solve the doubts of the masses. At this stage, many government departments have established government website and Weibo, but there are still a series of problems. For example, after the establishment of the government website and Weibo, the public's trust was lost because the information was not updated in time and the masses' doubts were not promptly reported. Therefore, the government website and Weibo platform need to update and release information related to the production and life of the masses in time, and answer the public's questions in a timely manner. In particular, the development potential of Weibo and WeChat platforms is relatively large, and government departments need to improve their administrative efficiency, integrate the network platforms of various regions and enhance the public's trust of government information through the release of information and interaction.

\subsection{Building a Government Internet Public Opin- ion Monitoring System}

In the process of Internet public opinion monitoring, information technology brings certain opportunities and challenges ${ }^{[7]}$. At this stage, the monitoring of Internet public opinion by the government departments is mainly on the security, which requires the construction of an effective government Internet public opinion monitoring system to fully play the role of this system: First, using the Internet to understand social conditions and public opinions, and obtaining and analyzing more real public appeals; Second, timely understanding and collecting public opinions related to the government departments and track them; Third, mastering the process, changes, and future development of emergencies and public opinions, and providing convenience for the government to reasonably choose intervention time and measures; Fourth, stopping and punishing timely illegal acts to avoid the spread and uncontrol of illegal public opinions; Fifth, government departments need to improve relevant policies and measures in time, rationally adjust social relations, and provide support for the smooth development of government decision-making. In addition, the government Internet public opinion monitoring system can construct by using e-government private network, terminal storage and service equipment with the help of the storage and computing functions in the cloud platform, and use relevant procedures to provide information collection, processing analysis, public opinion management and other services for the government. In the process of constructing the government Internet public opinion monitoring system, relevant personnel need to take the provincial administrative division as the basis, set up in the city and county level by level, establish an Internet public opinion data center, 
and improve the comprehensive and real-time nature of the Internet public opinion monitoring.

\section{Conclusion}

In summary, in the big data era, Internet public opinion, as a network public opinion, has greatly affected government management ${ }^{[8]}$. Internet public opinion is characterized by many types of issues, short duration breaks, content conflicts, etc., but there is a great public opinion impact. Traditional media also use new media platforms to promote the development of public opinions, which requires relevant departments to strengthen their understanding of characteristics of Internet public opinion in the big data era, and use big data technology to guide the public opinion of traditional media, laying a foundation for government departments to conduct social governance.

\section{References}

[1] Jinguo Liang. Analysis of Internet Public Opinion and Social Governance in the Big Data Era[J]. Information and Computer (Theoretical Edition), 2019 (10):211-213.
[2] Ranting $\mathrm{Xu}$. Discussion on Internet Public Opinion and Social Governance in the Big Data Era[J]. Journal of Propagation, 2019, 3(08):245.

[3] Ying Jing. Responding Reasonably to Internet Public Opinion and Improving Local Government Credibility[J]. People's Forum, 2018(16):62-63.

[4] Jie Yang, Yifan Zhang. Research on Internet Public Opinion and Social Governance in the Big Data Era[J]. Intelligence, 2018(11):244.

[5] Qingsong Wang. Analysis of the Role and Problems of Internet Public Opinion in Social Governance[J]. Journal of Fuzhou Party School, 2017(05):28-31.

[6] Dejing Ren. Using Internet Public Opinion to Conduct Social Governance under the Background of Big Data Era[J]. Shenyang Cadre Journal, 2016, 18(03):41-43.

[7] Shuoyang Zhang. Research on Internet Public Opinion and Network Social Governance in the Big Data Era[J]. Informatization Construction, 2016(04):1011 .

[8] Bing Yao. The Test of Internet Public Opinion on Social Governance[J]. Legality Vision, 2016 (07):175176 . 